NASA/TM-2006-214373

\title{
Optimal Control of Shock Wave Turbulent Boundary Layer Interactions Using Micro-Array Actuation
}

Bernhard H. Anderson

Glenn Research Center, Cleveland, Ohio

Jon Tinapple

Air Force Research Laboratory

Wright-Patterson Air Force Base, Dayton, Ohio

Lewis Surber

Universal Technology Corporation, Dayton, Ohio 


\section{NASA STI Program . . . in Profile}

Since its founding, NASA has been dedicated to the advancement of aeronautics and space science. The NASA Scientific and Technical Information (STI) program plays a key part in helping NASA maintain this important role.

The NASA STI Program operates under the auspices of the Agency Chief Information Officer. It collects, organizes, provides for archiving, and disseminates NASA's STI. The NASA STI program provides access to the NASA Aeronautics and Space Database and its public interface, the NASA Technical Reports Server, thus providing one of the largest collections of aeronautical and space science STI in the world. Results are published in both non-NASA channels and by NASA in the NASA STI Report Series, which includes the following report types:

- TECHNICAL PUBLICATION. Reports of completed research or a major significant phase of research that present the results of NASA programs and include extensive data or theoretical analysis. Includes compilations of significant scientific and technical data and information deemed to be of continuing reference value. NASA counterpart of peer-reviewed formal professional papers but has less stringent limitations on manuscript length and extent of graphic presentations.

- TECHNICAL MEMORANDUM. Scientific and technical findings that are preliminary or of specialized interest, e.g., quick release reports, working papers, and bibliographies that contain minimal annotation. Does not contain extensive analysis.

- CONTRACTOR REPORT. Scientific and technical findings by NASA-sponsored contractors and grantees.
- CONFERENCE PUBLICATION. Collected papers from scientific and technical conferences, symposia, seminars, or other meetings sponsored or cosponsored by NASA.

- SPECIAL PUBLICATION. Scientific, technical, or historical information from NASA programs, projects, and missions, often concerned with subjects having substantial public interest.

- TECHNICAL TRANSLATION. Englishlanguage translations of foreign scientific and technical material pertinent to NASA's mission.

Specialized services also include creating custom thesauri, building customized databases, organizing and publishing research results.

For more information about the NASA STI program, see the following:

- Access the NASA STI program home page at http://www.sti.nasa.gov

- E-mail your question via the Internet to help@sti.nasa.gov

- Fax your question to the NASA STI Help Desk at 301-621-0134

- Telephone the NASA STI Help Desk at 301-621-0390

- Write to:

NASA STI Help Desk

NASA Center for AeroSpace Information 7115 Standard Drive Hanover, MD 21076-1320 
NASA/TM-2006-214373

AIAA-2006-3197

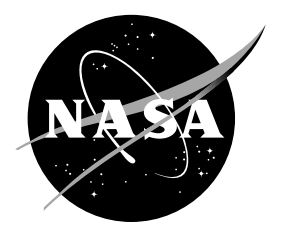

\section{Optimal Control of Shock Wave Turbulent Boundary Layer Interactions Using Micro-Array Actuation}

Bernhard H. Anderson

Glenn Research Center, Cleveland, Ohio

Jon Tinapple

Air Force Research Laboratory

Wright-Patterson Air Force Base, Dayton, Ohio

Lewis Surber

Universal Technology Corporation, Dayton, Ohio

Prepared for the

Third Flow Control Conference

sponsored by the American Institute of Aeronautics and Astronautics

San Francisco, California, June 5-8, 2006

National Aeronautics and

Space Administration

Glenn Research Center

Cleveland, Ohio 44135 
This work was sponsored by the Fundamental Aeronautics Program at the NASA Glenn Research Center.

Level of Review: This material has been technically reviewed by technical management.

Available from

NASA Center for Aerospace Information 7115 Standard Drive

Hanover, MD 21076-1320
National Technical Information Service 5285 Port Royal Road Springfield, VA 22161

Available electronically at http://gltrs.grc.nasa.gov 


\title{
Optimal Control of Shock Wave Turbulent Boundary Layer Interactions Using Micro-Array Actuation
}

\author{
Bernhard H. Anderson \\ National Aeronautics and Space Administration \\ Glenn Research Center \\ Cleveland, Ohio 44135 \\ Jon Tinapple \\ Air Force Research Laboratory \\ Wright-Patterson Air Force Base \\ Dayton, Ohio 45433 \\ Lewis Surber \\ Universal Technology Corporation \\ Dayton, Ohio 45432
}

\begin{abstract}
The intent of this study on micro-array flow control is to demonstrate the viability and economy of Response Surface Methodology (RSM) to determine optimal designs of micro-array actuation for controlling the shock wave turbulent boundary layer interactions within supersonic inlets and compare these concepts to conventional bleed performance. The term micro-array refers to micro-actuator arrays which have heights of $25 \%$ to $40 \%$ of the undisturbed supersonic boundary layer thickness. This study covers optimal control of shock wave turbulent boundary layer interactions using standard micro-vane, tapered micro-vane, and standard micro-ramp arrays at a free stream Mach number of 2.0. The effectiveness of the three micro-array devices was tested using a shock pressure rise induced by the $10^{\circ}$ shock generator, which was sufficiently strong as to separate the turbulent supersonic boundary layer. The overall design purpose of the micro-arrays was to alter the properties of the supersonic boundary layer by introducing a cascade of counter-rotating micro-vortices in the near wall region. In this manner, the impact of the shock wave boundary layer (SWBL) interaction on the main flow field was minimized without boundary bleed.
\end{abstract}

\section{NOMENCLATURE}

$\begin{array}{ll}\text { AIP } & \text { Aerodynamic Interface Plane } \\ \text { Ap } & \text { Micro-Actuator Angle-of-Incidence } \\ \text { AS } & \text { Across the Shock Bleed Configuration, (See Ref. 2) } \\ \text { c } & \text { Micro-Actuator Chord Length } \\ \text { CCF } & \text { Central Composite Face-Centered } \\ \text { CFD } & \text { Computational Fluid Dynamics } \\ \text { DOE } & \text { Design of Experiments } \\ \text { DS } & \text { Downstream of Shock Bleed Configuration, (See Ref. 2) } \\ \text { DP/P } \mathrm{P}_{0} & \text { Total Pressure Change } \\ \mathrm{h} & \text { Micro-Actuator Height } \\ \mathrm{hy} & \text { Tunnel Width, } 15 \mathrm{~cm} . \\ \mathrm{hz} & \text { Tunnel Height, } 15 \mathrm{~cm} . \\ \mathrm{H}_{\mathrm{tr}} & \text { Transformed Form Factor, (See Ref. 2) }\end{array}$




$\mathrm{M}_{0}$
$\mathrm{M}_{\text {BLEED }} / \mathrm{M}_{\text {BL1 }}$
$\mathrm{n}$
$\mathrm{P}_{0}$
$\mathrm{RSM}$
$\mathrm{SWBL}$
$\mathrm{s}$
$\mathrm{T}_{0}$
$\mathrm{US}$
Xaip
Xp
$\mathrm{W}_{\text {bleed }}$
$\mathrm{W}_{0}$
$\mathrm{~W}_{1}$
$\mathrm{~W}_{2}$
$\delta$
$\delta^{*}$
$\delta_{\text {shk }}$
$\theta$

Tunnel Mach Number

Bleed Mass Flow Ratio, (See Ref. 2)

Number of Micro-Actuator Pairs

Tunnel Total Pressure

Response Surface Methodology

Shock Wave Boundary Layer

Spanwise Micro-Actuator Spacing

Tunnel Total Temperature

Upstream of Shock Bleed Configuration, (See Ref. 2)

Streamwise Location Reference (AIP) Plane

Location of Micro-Actuator Array

Bleed Mass Flow

Capture Mass Flow

Weighting Function for Total Pressure Change, DP/ $\mathrm{P}_{0}$

Weighting Function for Transformed Boundary Layer Form Factor, $\mathrm{H}_{\mathrm{tr}}$

Shock Generator Angle

Compressible Boundary Layer Displacement Thickness

Boundary Layer Thickness At Shock Impingement Location

Compressible Boundary Layer Momentum Thickness

\section{INTRODUCTION}

Supersonic inlet performance is directly related to the way the boundary layer develops through the inlet. Uncontrolled viscous effects related to boundary layer growth and interactions can cause performance degradations that may seriously limit the effectiveness of the inlet. A boundary layer developing through strong adverse pressure gradients tend to thicken rapidly and have velocity profiles "less full" than boundary layer profiles with zero pressure gradient. Interactions between boundary layer and shock waves also cause the boundary layer thickness to change and distort the velocity profile. These changes affect the inviscid flow field by increasing the likelihood of separation and reducing inlet total pressure recovery. The adverse effects associated with the boundary layer can be partially eliminated by using a "bleed" system to control boundary layer development through the inlet. The bleed system usually removes the low momentum portion of the boundary layer through porous sections, slots, or scoops. In this way, the size and characteristics of the boundary layer are in some way controlled. A large performance penalty is incurred, however, in maintaining a "healthy" boundary layer in supersonic inlets by "bleeding" off the low momentum portion of the boundary layer. The bleed mass flow is not usually reinjected into the inlet, so part of the capture mass flow is lost. To compensate for this loss in mass flow, a larger nacelle may be needed which would increase the friction drag and inlet weight. In addition, the bleed flow is usually vented overboard through bleed exits, a phenomenon which also incurs a drag penalty. Therefore it is desirable to minimize the amount of boundary layer bleed and/or develop alternate methods for maintaining good internal aerodynamic performance.

There have been excellent studies published on the control of shock wave turbulent boundary layer interactions in supersonic mixed compression inlets by Tjonneland ${ }^{(1)}$, Fukuda, Hingst, and Reshotko ${ }^{(2)}$, and Syberg and $\mathrm{Konsek}^{(3)}$. In each study, the design objective was to maintain a "healthy" boundary layer development throughout the supersonic inlet system. Therefore, an intermediate parameter had to be defined which characterizes the "health" of the boundary layer within the supersonic inlet. In the experimental study by Fukuda, Hingst, and Reshotko, the "health" of the supersonic inlet boundary was characterized by a transformed form factor $\mathrm{H}_{\mathrm{tr}}$. The transformed form factor $\mathrm{H}_{\mathrm{tr}}$ is defined in the exactly same way as the 
incompressible form factor. However, it is applied in the compressible flow regime. It is used in compressible boundary layer bleed studies to compress the Mach number effect on the measured boundary layer properties

This research study on micro-actuator array flow control is a collaborative effort between the AFRL Flight Vehicles Directorate (AFRL/VAAI) and NASA Glenn Research Center (NASA/GRC) to develop and demonstrate advanced flow control techniques for supersonic mixed compression inlets. The AFRL Flight Vehicles Directorate has focused recent effort on the advancement of propulsion integration technologies associated with LRSA (Long Range Strike Aircraft). The goal of this effort has been to define and develop high payoff advanced technology approaches for mixed compression inlets operating in the Mach 2.0 to 4.0 speed regime. In addition, NASA/GRC is also focusing a portion of its micro-flow control research effort on commercial and business type aircraft in the speed range Mach 1.6 to 2.0. Therefore, the collaborative effort also provides technology interchange between the military and commercial side of aerodynamic research. The collaboration between AFRL/VAAI and NASA/GRC combines CFD analysis, Design-of-Experiments (DOE) methodologies ${ }^{(4)}$ and experimental test, from small scale subcomponent applications to low-cost DOE based large scale isolated inlet models, to demonstrate reliable high inlet performance as well as unprecedented efficiency of the design/development process. The matured plan for collaboration will involve CFD capabilities in NASA, AFRL, industry and academia. NASA/GRC has developed the baseline CFD analysis and DOE investigation of advanced flow control "fail safe" actuators along with "Proof-ofConcept" CFD analysis of the integration of micro-actuator devices into "real" supersonic external and mixed compression inlet systems. The AFRL/VA Computational Branch (VAAC) has become involved as well, helping to guide test planning at AFRL by providing CFD analysis of wind tunnel hardware. In a collaborative program with NASA/GRC, they are also assisting in providing comparisons of actuator CFD analysis between the NASA WIND code and the AFRL AVUS code using formal statistical analysis. Supplemental basic research into the physics of SWBL interactions will be accomplished by the Univ. of Illinois (CFD Analysis) and Cambridge Univ. (Experimental Studies). Their combined work will provide insight into the fundamental aerodynamic characteristics of "non-bleed" shock wave boundary layer control, both with regards to performance and inlet stability

This paper is the first in a series of studies within the AFRL/VAAI and NASA/GRC collaboration which examines fundamental type shock wave turbulent boundary layer (SWBL) interactions to determine whether they can be managed adequately without boundary layer bleed. There were three objectives in this study that were considered important, namely: (1) to establish the ability of micro-array flow control to manage the shock wave turbulent boundary layer interactions in supersonic inlets, (2) to determine the "design" characteristics of micro-array actuation, and (3) to evaluate the effectiveness of micro-array flow control, relative to conventional inlet boundary layer bleed. The payoff associated with the collaborative AFRL/VAAI NASA/GRC project is the future demonstration of reliable high performance in practical, flight vehicle-integrated supersonic inlets as well as unprecedented efficiency of the overall process of air intake design and development for future aircraft systems.

\section{RESULTS AND DISCUSSION}

The following section will cover the overall design approach to micro-actuator flow control, the CFD analysis of micro-actuator flow control, the optimization of micro-actuator flow control, a performance comparison with conventional inlet boundary layer bleed, the generalized

design guidelines to micro-actuator flow control, and finally, the aerodynamic properties of micro-actuator flow fields. 


\section{Design Approach to Optimal Micro-Actuator Array Flow Control}

The study on micro-array flow control centers on the NASA/GRC 15 x $15 \mathrm{~cm}$. Supersonic Wind Tunnel in which a $10^{\circ}$ shock generator was installed to induce a strong shock wave turbulent boundary later interaction, Figures 1 and 2. Micro-array devices were positioned upstream of the SWBL interaction, Figure 1, to generate a cascade of micro-vortices in the near wall region of the supersonic boundary layer. The study covered optimal control of shock wave turbulent boundary layer interactions using standard micro-vanes, tapered micro-vane, and standard micro-ramp arrays, Figures 3 through 11, operating at a free stream Mach number of 2.0. The overall design purpose of the micro-actuation is to alter the properties of the supersonic boundary layer by introducing a cascade of counter-rotating micro-vortices in the near wall region. The properties of the micro-arrays are described in the last section of this paper entitled "Aerodynamic Properties of Micro-Actuator Flow Fields". The effectiveness of the three types of micro-actuator array devices was tested using the shock pressure rise induced by the $10^{\circ}$ shock generator, which was sufficiently strong as to separate the turbulent supersonic boundary layer.

The factor (design) variables are listed in Table 1 and are the number of co-rotating microactuator pairs (n), the micro-actuator geometric angle-of-incidence (Ap), the height of the microactuator in $\mathrm{mm}$. (h), the chord length of the micro-actuator in $\mathrm{mm}$. (c), and the location of the micro-actuator arrays upstream of the inviscid shock impingement point on the tunnel floor in $\mathrm{cm}$. (Xp). The variables that were held constant in this study are presented in Table 2, and include the tunnel Mach number $\mathrm{M}_{0}$, the shock generator angle $\delta$, the tunnel total pressure $\mathrm{P}_{0}$, and the tunnel total temperature $\mathrm{T}_{0}$. Table 3 presents the response variables which included the microactuator array area averaged total pressure change $\left(\mathrm{DP} / \mathrm{P}_{0}\right)$ from the baseline or uncontrolled SWBL interaction flow field, the area averaged compressible boundary layer displacement thickness $\left(\delta^{*}\right)$ at the AIP (or reference plane) located $10.0 \mathrm{~cm}$. downstream of the inviscid shock wave impingement on the tunnel floor, the area averaged compressible momentum thickness at the AIP $(\theta)$, and the area averaged boundary layer transformed form factor $\left(\mathrm{H}_{\mathrm{tr}}\right)$. The location of the micro-actuator arrays relative to the baseline shockwave boundary layer interaction is shown in Figure 13 along with the reference (AIP) survey plane. At a streamwise location Xp of $6.0 \mathrm{~cm}$, the micro-actuators are partially within the separated region.

The DOE strategy selected was a Central Composite Face-Centered (CCF) design, Table (4). This strategy resulted in three sets of 27 unique CFD experimental cases, one set for each of the three micro-actuator array devices under consideration. This particular DOE design, like most DOE strategies, varied more than one factor at a time. Further, this layout of 27 cases permitted the estimation of both linear and curvilinear effects as well as two-factor interactive or synergistic effects among the factor variables. A graphical representation of the Central Composite FaceCentered (CCF) DOE used in this study is presented in Figure 13. The DOE cases are represented in this figure by the circular symbols, where the locations of the symbols on the cube designate the factor values. This DOE is called is called a composite design because the layout of cases are composed of a fractional factorial part and a quadratic part. The full factorial part is composed of the $2^{5}$ or 32 cases which are represented by the eight corner location in each of the four corner cubes in Figure 13. However, since this DOE is composed of a $1 \frac{1}{2}$ fractional factorial design, there is only $2^{5-1}$ or 16 factorial cases, and these have been designated as the symbols in each of the four corner cubes in Figure 13. The remainder of the cases is the quadric part of the DOE. All together, there are 27 cases in a CCF design with five factor variables. Notice the balanced layout of cases in Figure 13. These layouts represent the smallest number of DOE cases that allow for the evaluation of the linear and curvilinear effects as well as all the two-factor or first order interactions.

One critical aspect of Response Surface Methodology ${ }^{(4)}$ (RSM) is its ability to identify, prioritize, and examine statistical interactions among the factors (design) variables. Knowledge of these statistical interactions is critical for achieving optimal micro-array designs. A statistical 
interaction exists between two independent factor variables $\mathrm{X} 1$ and $\mathrm{X} 2$ when the effect of $\mathrm{X} 1$ on response variable $\mathrm{Yi}$ is affected by the value of $\mathrm{X} 2$. In other words, the effect of factor $\mathrm{X} 1$ on response $\mathrm{Yi}$ is not unique, but changes as a function of $\mathrm{X} 2$. This type of behavior is often called a synergistic effect and its understanding is very critical in the optimization process of micro-array flow control devices.

\section{Analysis of Micro-Actuator Flow Control}

Each of the $3 \times 27$ cases, representing the DOE design for the tapered vanes, Figure 3, standard ramps, Figure 6, and standard vanes, Figure 9, were run with a Reynolds-averaged Navier Stokes WIND code $\mathrm{e}^{(5-6)}$. The DOE matrixes of cases, for each of the micro-actuators studied, were identical to Table 4, where the nomenclature definition of the micro-actuator factor variables are defined in Figures 5, 8 and 11. In the present study, the individual micro-actuators were incorporated into the grid topology, which are shown in Figures 4, 7 and 10, for the tapered vanes, standard ramps, and standard vanes respectively. The complete grid was composed of three blocks, an upstream block, a working block represented by Figures 4, 7 and 11, and a downstream block. Since the need existed to economize, because of the large number of cases to be run, and to guarantee proper grid resolution in the neighborhood of the micro-actuators, only a single vane or half-ramp geometry was considered. Symmetry boundary conditions were then applied to the grid side walls, and inviscid wall boundary conditions were applied to the shock generator and top wall surfaces. Each of the $3 \times 27$ or 81 cases were run with a grid containing 263,552 mesh points, where the working block consisted of 50x45x64 mesh points. Hence, in this study, there were 45 grid points to resolve the flow across the radius of the vortex induced by the micro-actuators.

Although the grid topology allowed for a boundary layer development along the microactuators themselves, a statistical error study was initiated by Anderson, Tinapple, and, Surber ${ }^{(7)}$ to determine whether it was necessary to resolve the boundary layer on the micro-actuator surfaces. The results indicated that there was no statistical difference between the DOE response variables defined in Table 3, as a result of the different wall boundary conditions applied to the micro-actuator surfaces. Hence, it was not necessary to resolve the micro-actuator surface boundary layer in the grid topology. A statistical error study was also initiated by Anderson, Tinapple, and, Surber ${ }^{(7)}$ to determine the impact of the assumed turbulence model. Two sets of paired observation, each containing nine different micro-actuator geometries, were evaluated using both the 2-equation Shear Stress turbulence model and the Spalart-Allmaras turbulence model contained in the WIND Navier Stokes code. Again, the results indicated that there was no statistical difference between the DOE response variables as a result of turbulence model. Hence, the shock wave boundary layer interaction was not sensitive to turbulence model when optimal micro-actuator array devices were present in the flow field.

\section{Optimal Micro-Actuator Array Flow Control}

To illustrate the potential of Response Surface Methods (RSM) to determine optimal designs of micro-array actuation for controlling the shock wave turbulent boundary layer interactions within supersonic inlets, the design objectives must be clearly stated in terms of the DOE response variables presented in Table 3. Of the four response variables listed, the main objectives are to maximize the total pressure difference $\left(\mathrm{DP} / \mathrm{P}_{0}\right)$ and to minimize the boundary layer transformed form factor $\left(\mathrm{H}_{\mathrm{tr}}\right)$ downstream of the shock wave boundary layer interaction. The two other response variables $\left(\delta^{*}\right)$ and $(\theta)$ are left unconstrained in optimization process. Unfortunately, $\left(\mathrm{DP} / \mathrm{P}_{0}\right)$ does not maximize in the same location in design space as $\left(\mathrm{H}_{\mathrm{tr}}\right)$ is minimized. Hence, a multi-object methodology must be used to optimize micro-actuator array

$$
D=\sum_{i=1}^{N} w_{i} \eta_{i}
$$


flow control. To accomplish the multi-objective optimization, a desirable function is defined such that

where

$$
\eta_{1}=\frac{Y_{1}-Y_{1, \min }}{Y_{1, \max }-Y_{1, \min }}
$$

and

$$
\eta_{2}=1.0-\frac{Y_{2}-Y_{2, \min }}{Y_{2, \max }-Y_{2, \min }}
$$

The normalized response variables $\eta_{1}$ and $\eta_{2}$ are related to the actual response variables through the equations

$$
\begin{aligned}
& Y_{2}=H_{t r} \\
& Y_{1}=D P / P_{0}
\end{aligned}
$$

while the weighting functions $w_{1}$ and $w_{2}$ must satisfy the condition that

$$
\sum_{i=1}^{N} w_{i}=1.0
$$

The results of the multi-objective optimization are presented in Table 5 in terms of the weighting functions $w_{\mathrm{i}}$ and the micro-actuator configurations, i.e. the 300 series configuration for tapered micro-vanes, the 400 series for standard micro-ramps, and the 500 series configuration for standard micro-vanes. The weighting function $w_{1}$ was chosen to be $0.0,0.5$, and 1.0 for this study. Thus for a weighting value $w_{1}$ equal to 0.0 , the transformed form factor $\left(\mathrm{H}_{\mathrm{tr}}\right)$ is minimized, while for a weighting function value $w_{1}$ equal to 1.0 , the total pressure difference $\left(\mathrm{DP} / \mathrm{P}_{0}\right)$ downstream of the shock wave boundary layer interaction is maximized.

In order to judge the adequacy of the response surface representation, a statistical study was made between the DOE prediction from the computed response surface, Table (6), and a paired set of CFD analysis results, Table 7, each for the optimal micro-actuator arrays defined in Table 5. The observations presented in Tables 6 and 7 have been ordered such that the two sets of $4 \times 9$ observations can be tested as a paired t-test. In a paired t-test, the mean of the sample difference and the standard deviation of the sample difference are computed and the following $\mathrm{t}$ statistic determined:

$$
t^{*}=\frac{\left|\frac{1}{N} \sum_{j=1}^{N} \Delta_{j}\right|}{\sqrt{\sum_{j=1}^{N} \frac{\left(\Delta_{j}-\bar{\Delta}\right)^{2}}{(N-1)}}}
$$

where $\Delta_{j}=\left(Y_{1}-Y_{2}\right)_{j}$ is the difference between each of the N-pairs of response variables in the two data sets tabulated in Tables 6 and 7 and $\bar{\Delta}$ is the mean of the sample difference. In a paired ttest, if the expression

$$
t^{*}<t\left(0.975, v_{p}\right)
$$

is valid, the response variables from the first data are not statistically different from the response variables from the second the data set at the $95 \%$ confidence level. Conversely, the response variables from the first data set are statistically different from the response variables in the second data set if the following expression is valid:

$$
t^{*}>t\left(0.975, v_{p}\right)
$$

where $t\left(0.975, v_{p}\right)$ is the $95 \%$ confidence $\mathrm{t}$-value from the t-tables for $v_{\mathrm{p}}$ degrees of freedom, which in this example would be eight, i.e., number of observation minus one. The statistical comparison between the DOE response surface predictions, Table 6, and the CFD analysis 
results, Table 7, are presented in Table 8 and indicate that there is no significant statistical difference between the two sets of observations at the 95\% confidence level. Even though there are numerical differences between the two prediction methods, these differences are not statistically meaningful. Therefore, the optimal response surface representation for $\left(\mathrm{DP} / \mathrm{P}_{0}\right)$ and $\left(\mathrm{H}_{\text {tr }}\right)$ presented in Figures 13 and 14 are in very good agreement with the CFD analysis. It is also obvious from Figures 13 and 14 that maximizing the total pressure recovery is not compatible with minimizing the impact of the shock wave turbulent boundary layer interaction by using micro-actuator devices. However, optimal boundary layer control can be achieved with gains in total pressure recovery.

\section{Comparison With Inlet Boundary Layer Bleed}

As indicated in the previous section, it is possible to manage the shock wave boundary layer interaction within a supersonic mixed compression inlet with micro-actuator devices, whether these devices are tapered micro-vanes, standard micro-ramps, or standard micro-vanes. This property of micro-actuator devises is shown in Figure 14a, which presents the transformed form factor $\mathrm{H}_{\mathrm{tr}}$ as a function of actuator angle-of-incidence. It shows a decreasing the transformed boundary layer form factor $\mathrm{H}_{\mathrm{tr}}$ with increasing geometric angle-of-incidence, even suggesting a minimum plateau. In contrast, the results of the experimental study by Fukuda, Hingst, and Reshotko ${ }^{(2)}$ showed that the transformed boundary layer form factor $\mathrm{H}_{\mathrm{tr}}$ directly after the shock interaction also decreased with increasing bleed until a plateau was reached. This characteristic is presented in Figure 14b. The level of the plateau was found to be dependant on the placement of the bleed region relative to the shock induced pressure rise for given type of bleed. The amount of bleed necessary to reach the $\mathrm{H}_{\text {tr }}$ plateau was between $30 \%$ and $40 \%$ of the boundary layer mass flow before the shock wave boundary layer interaction. This optimal amount of boundary layer bleed translated into $1.87 \%$ of the inlet capture mass flow $\left(\mathrm{W}_{\text {bleed }} / \mathrm{W}_{0}\right)$. In comparing microactuator boundary layer control, Figure 14a, with inlet boundary layer bleed control, Figure (14b), it is apparent each can achieve the same level of $\mathrm{H}_{\mathrm{tr}}$ reduction in the boundary layer downstream of the shock wave boundary layer interaction. It is also apparent the micro-actuator angle-ofincidence plays the same role as bleed mass flow ratio in the boundary layer management process, and that they have very similar behavioral characteristics.

There are, however, very important behavioral differences between controlling shock boundary layer interactions with micro-actuator flow control instead of conventional boundary layer bleed. These differences will lead to major inlet design changes. The boundary layer displacement thickness downstream of the interaction was substantially larger with microactuator flow control than with boundary layer bleed ${ }^{(7)}$. This will require re-contouring the inlet geometry, i.e. enlarging the internal flow passage, while decreasing the overall size of the supersonic inlet. For example, a supersonic inlet designed to have $10 \%$ performance bleed will have a capture area sized for both the required engine weight flow and the $10 \%$ performance bleed amount. Therefore, with no performance bleed, the capture area will be $10 \%$ smaller and the overall nacelle drag will be reduced. In addition, micro-actuator flow control will also require the internal passage to be enlarged approximately $10 \%$ to accommodate an average thicker inlet boundary layer.

\section{Generalized Micro-Actuator Array Design Guidelines}

The optimal micro-actuator designs presented in Table 5 have been generalized by normalizing the optimal micro-actuator height $(\mathrm{h})$ and micro-actuator array streamwise location $(\mathrm{Xp})$ with respect to the boundary layer thickness at the shock wave impingement point $\left(\delta_{\text {shk }}\right)$. In addition, the micro-actuator chord length (c) and lateral spacing distance (s) have been scaled to the micro-actuator blade height (h). The results are presented in Table 9, and they represent 
generalized design guidelines to be applied to supersonic inlet problems. However, the guidelines presented in Table 9 showed not be used as "hard and fast" design rules, but rather as a centering point in the design space of a DOE matrix for supersonic inlet flow control.

For example, consider the 4060 Mixed Compression Supersonic Inlet that was used as the study vehicle by Fukuda, Hingst, and Reshotko ${ }^{(2)}$ to examine boundary layer bleed. In this inlet example, micro-ramp devices could be used to manage the second shock wave boundary layer interaction along the centerbody and the first shock wave boundary layer interaction along the cowl, thereby eliminating the performance bleed system. At a free stream Mach number of 2.5, the boundary layer thicknesses at these locations were nominally 0.187 and 0.125 inches respectively; hence the recommended micro-ramp heights would be 0.075 and 0.050 inches at these locations. These values were based on an optimal $\left(\mathrm{h} / \delta_{\text {shk }}\right)$ ratio of 0.40 . See Config. nvg 431 in Table 9. Therefore, the 4060 Mixed Compression Mach 2.5 Supersonic Inlet, with a 18.63 inch cowl (capture) diameter, would require 145 centerbody micro-ramps and 303 cowl micro-ramps based on the optimal design values presented in Table 9. The number of require micro-ramps is determined by the centerbody and cowl circumference at installation location and the optimal transverse spacing ratio from Table 9. This would be the DOE design center point, and the factor range could be 0.050 to 0.100 inches for the centerbody micro-ramp heights and 0.025 to 0.075 inches for the cowl micro-ramp heights. The entire DOE matrix is therefore established for a two factor DOE design, since the optimal $(\mathrm{c} / \mathrm{h})$ ratio would be held constant at 7.2 , and the optimal lateral spacing ratio $(\mathrm{s} / \mathrm{h})$ would be held fixed at a value of 7.5. Hence, the optimal micro-ramp actuator design could be experimental validated in as few as three tunnel runs for a "Main Effects" design or as many as nine tunnel runs for a Central Composite Face-Centered (CCF) design.

\section{Aerodynamic Properties of Micro-Actuator Flow Fields}

The overall design purpose of the micro-arrays was to alter the properties of the supersonic boundary layer by introducing a cascade of counter-rotating micro-vortices in the near wall region surrounding the inlet surfaces. In this manner, the impact of the SWBL interaction on the main flow field was minimized without boundary bleed. The arrays of the micro-ramp devices or pairs of micro-vanes devices whether tapered or standard, induce a vortex sheet composed of counter-rotating vortices that span the tunnel floor, where spanwise spacing of the vortex pairs is very important. Therefore, alternate regions of "upwash" and "downwash" are produce. This is illustrated in Figure 15 which presents the flow induced by the optimal micro-ramp configuration as total pressure contours that span the grid domain. On the average, the transformed form factor $\left(\mathrm{H}_{\mathrm{tr}}\right)$ has been reduced to the ideal incompressible flat plate value of 1.295 downstream of the SWBL interaction. Low energy flow tends to accumulate in the "upwash" region of the flow field and the boundary layer thickens relative to the baseline flow, see Figure 12. In the "downwash" region of the flow field, the boundary thins out relative to the baseline flow. This effect is shown in Figure 16, which presents a comparison the streamwise Mach number contours in a "downwash" cut, Figure 16a, and the contours in the "upwash" plane of the flow field, Figure $16 \mathrm{~b}$. Hence, the supersonic boundary layer is highly three dimensional.

It is also apparent the optimal micro-ramp arrays induced a "virtual surface" surrounding the wall surface. The region enclosed by the induced virtual surface is highly three dimensional, which can sustain a normal shock wave structure, Figure 16b. It is also very compliant. In other words, the properties in the region enclosed by the virtual surface are not that of a normal supersonic boundary layer. Although the characteristics of this region have not been studied in detail, they can support a shock wave interaction that would separate a normal supersonic boundary layer. Therefore, micro-ramp flow control is very practical for use in supersonic inlets, since they are "fail safe", structurally highly robust, and very affordable. In addition, time accurate CFD solutions indicate that optimal micro-ramp arrays can also stabilize the shock wave turbulent boundary layer interaction to both upstream and downstream disturbances. It is in 
stabilizing the mixed compression supersonic inlet that micro-actuator devices will play it most important role.

\section{SUMARY OF RESULTS}

To demonstrate the viability and economy of Response Surface Methodology (RSM) to determine optimal designs of micro-array actuation for controlling the shock wave turbulent boundary layer interactions, a study was initiated that considered three different micro-devices. These devices included standard micro-vanes, tapered micro-vanes, and standard micro-ramps arrays tested at a free stream Mach number of 2.0. The effectiveness of the three micro-array devices was examined using a shock pressure rise induced by the $10^{\circ}$ shock generator, which was sufficiently strong as to separate the turbulent supersonic boundary layer. All the devices had approximately the same reductions in $\mathrm{H}_{\mathrm{tr}}$ in the supersonic boundary layer downsteam of the SWBL interaction as conventional inlet boundary layer bleed. They also exhibited important behavioral differences from conventional inlet bleed that have major inlet design consequences. The boundary layer displacement thickness downstream of the interaction was substantially larger with micro-actuator flow control than with boundary layer bleed. The displacement thickness was sufficiently larger as to require re-contouring the inlet geometry, i.e. enlarging the internal flow passage, while decreasing the overall size of the supersonic inlet.

Optimal micro-ramp arrays alter the properties of the supersonic boundary layer by introducing a cascade of counter-rotating micro-vortices in the near wall region surrounding the tunnel surfaces.. They also induced a "virtual surface" surrounding the wall surface that was highly three dimensional and which could sustain a normal shock wave structure. The properties of the supersonic boundary layer were dramatically changed. These new characteristics can support a shock wave interaction that would separate a normal supersonic boundary layer. Therefore, micro-ramp flow control is very practical for use in supersonic inlets, since they are "fail safe", structurally highly robust, and very affordable.

\section{REFERENCES}

${ }^{(1)}$ Tjonneland, E., "The Design, Development, and Testing of a Supersonic Transport Intake System," AGARD-CP-91-71, paper presented at the 38th meeting of the AGARD Propulsion and Energetics Panel, Sandefjord, Norway, September 1971.

${ }^{(2)}$ Fukuda, M. K, Hingst, W. G., and Reshotko, E., "Control of Shock Wave-Boundary Layer Interactions by Bleed in Supersonic Mixed Compression Inlets," NASA CR-2595, August, 1975

${ }^{(3)}$ Syberg, J. and Konsek, J. L., "Bleed system design technology for supersonic inlets”, Jour. of Aircraft, Vol. 10, No. 7.

${ }^{(4)}$ Box, G. E. P., Hunter, W. G., and Hunter, J. S., "Statistics for Experimenters," John Wiley, New York

${ }^{(5)}$ NPARC Alliance, "The Wind-US Code", http://www/grc.nasa/www/Wind-US_docs [cited 13 June 2004.

${ }^{(6)}$ Bush, R. H., Power, G. D., and Towne, C. E., "Wind-US: The Production Flow Solver of the NPRAC Alliance”, AIAA-1998-0935, Januar7y 1998.

${ }^{(7)}$ Anderson, B. H., Tinapple, J., and Surber, L., "Optimal Micro-Array Actuation Control for Shock Wave Boundary Layer Interactions in Supersonic Inlets”, Proposed NASA TM, 2006. 


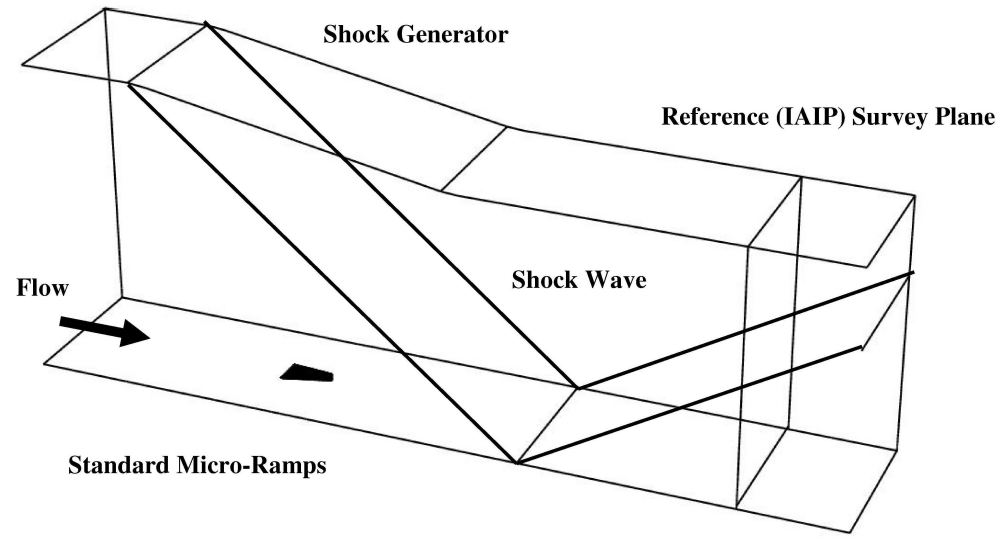

Figure (1): Schematic diagram showing the shock generator and standard micro-ramp actuators installed in the NASA/GRC $15 \times 15 \mathrm{~cm}$. Supersonic Wind Tunnel.

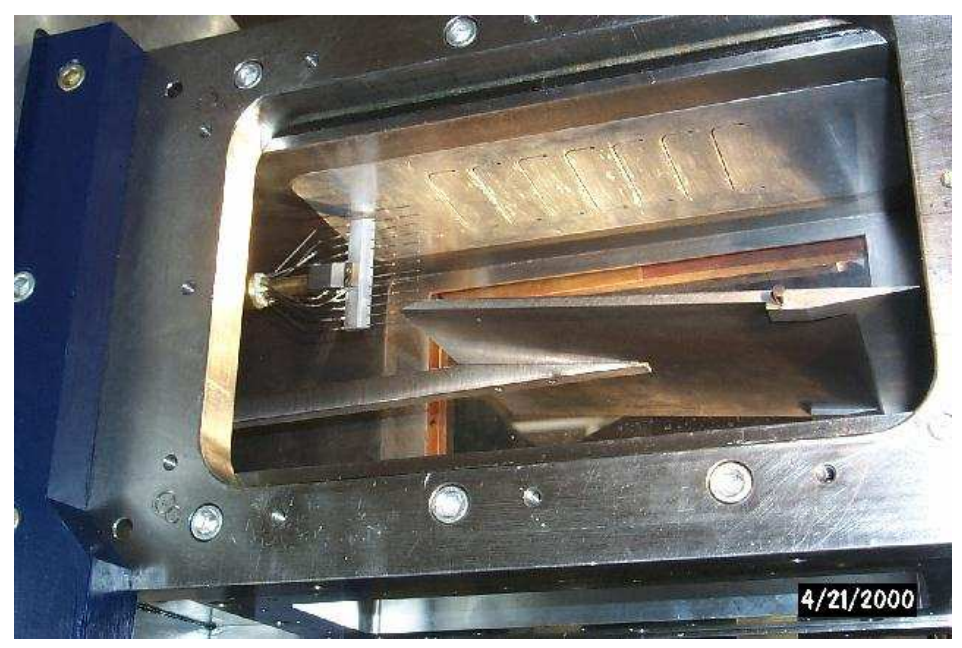

Figure (2): Photograph showing the NASA/GRC $15 \times 15 \mathrm{~cm}$. Supersonic Wind Tunnel.

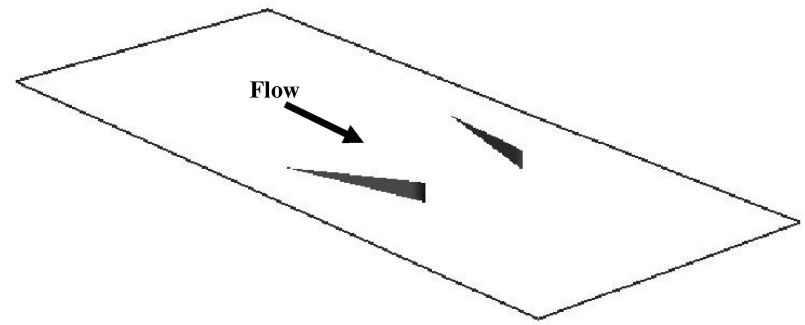

Figure (3): Schematic diagram showing tapered micro-vane actuators.

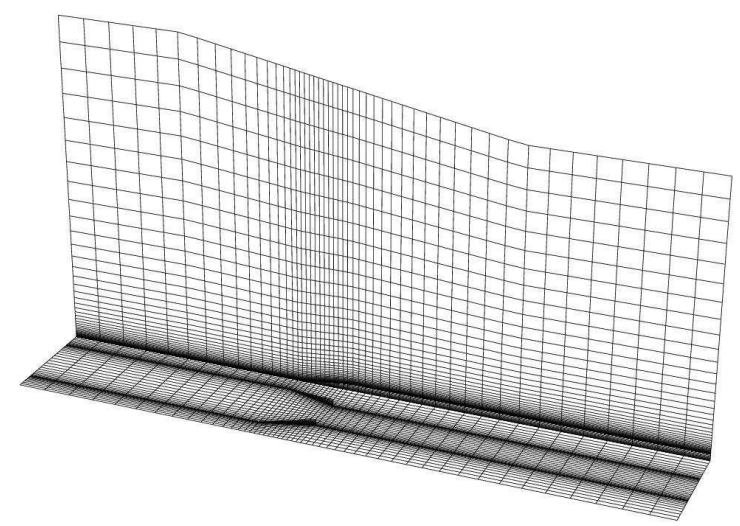

Figure (4): Grid topology of tapered micro-vane actuators.

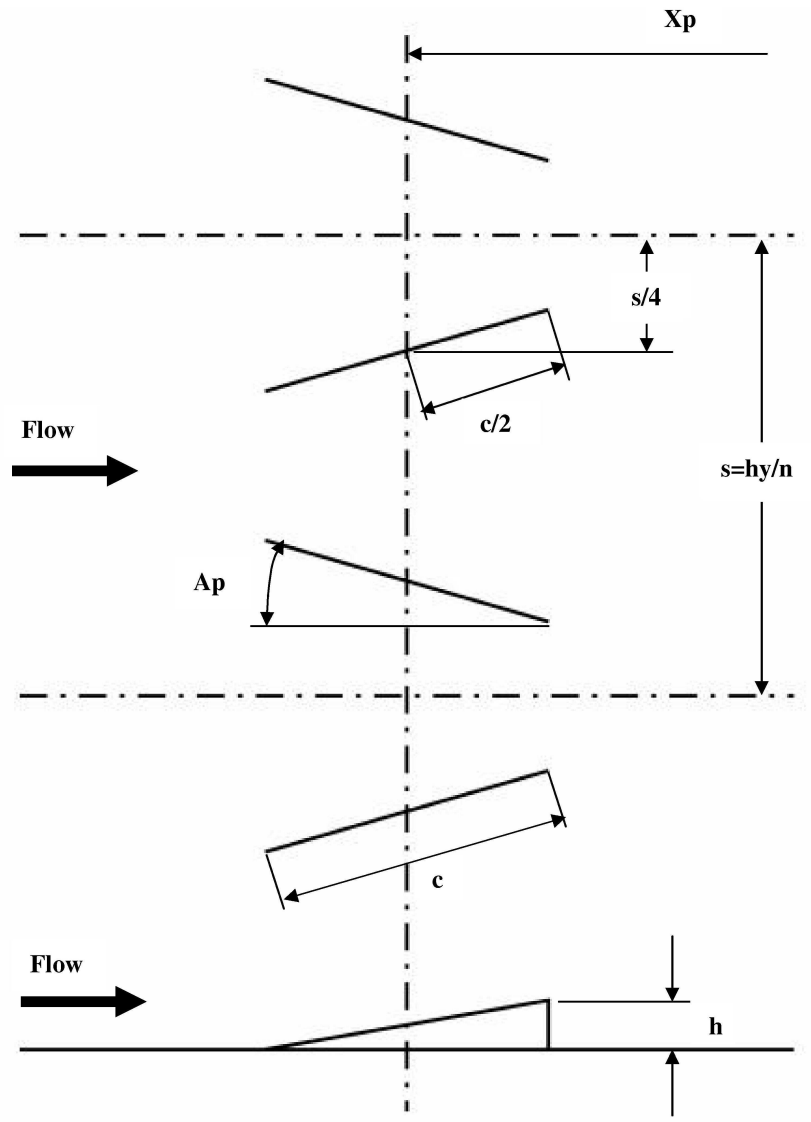

Figure (5): Geometry and nomenclature for tapered micro-vane actuactors. 


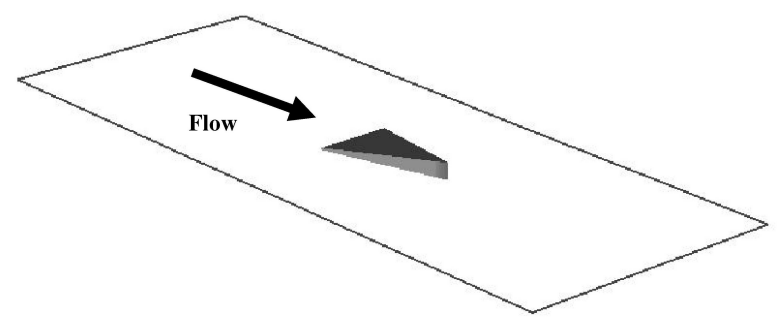

Figure (6): Schematic diagram showing standard micro-ramp actuators.

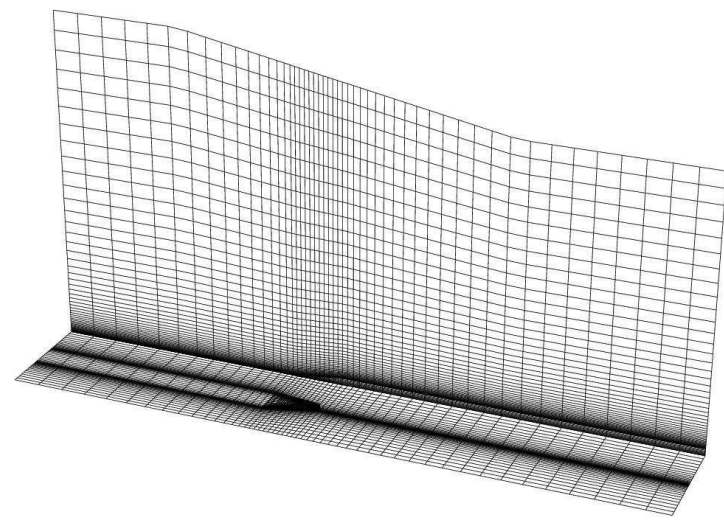

Figure (7): Grid topology of standard micro-ramp actuators.

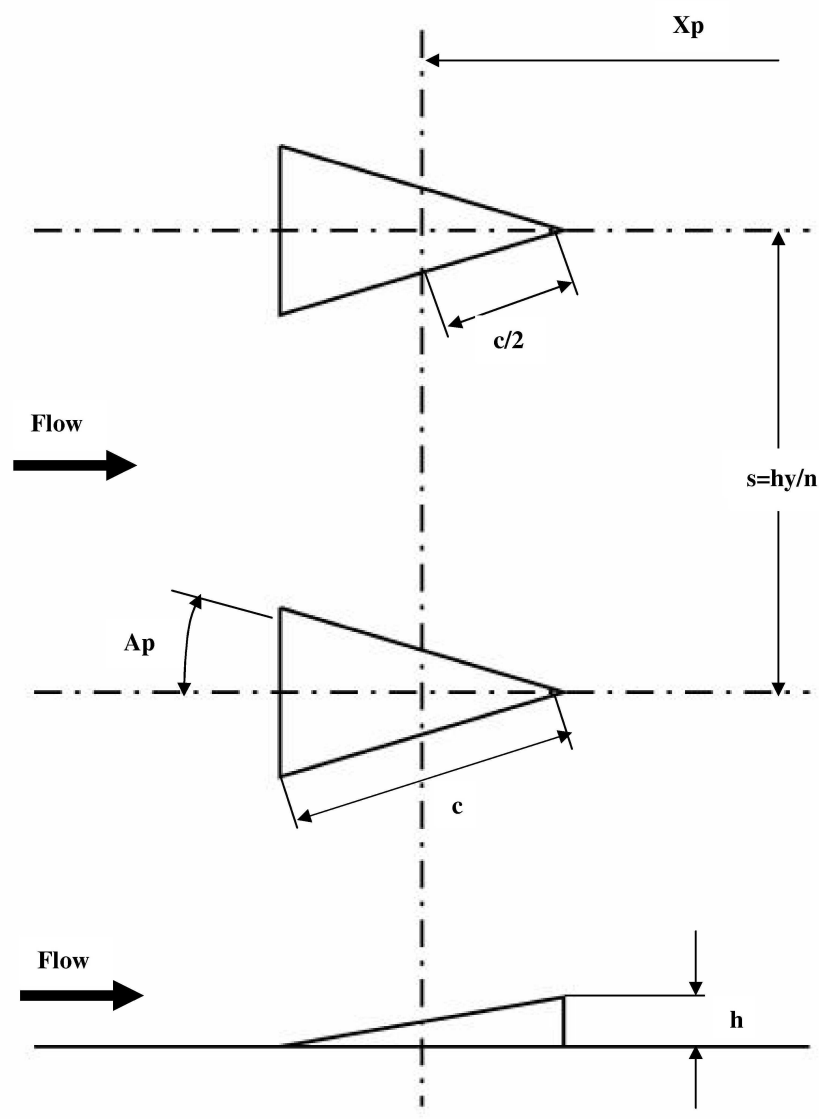

Figure (8): Geometry and nomenclature for standard micro-ramp actuactors.

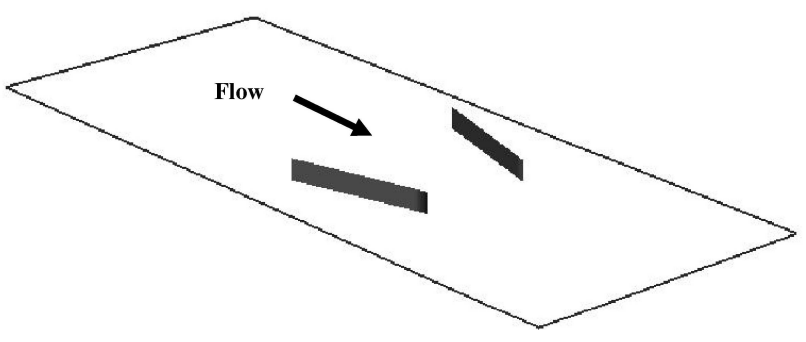

Figure (9): Schematic diagram showing standard micro-vane actuators.

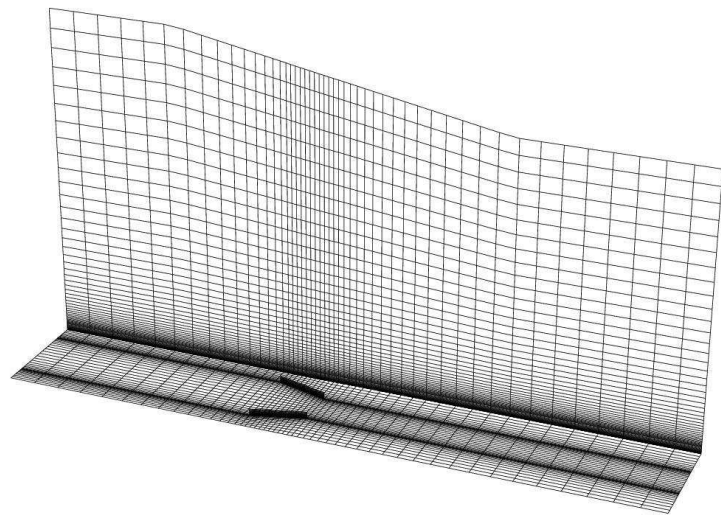

Figure (10): Grid topology of standard micro-vane actuators.

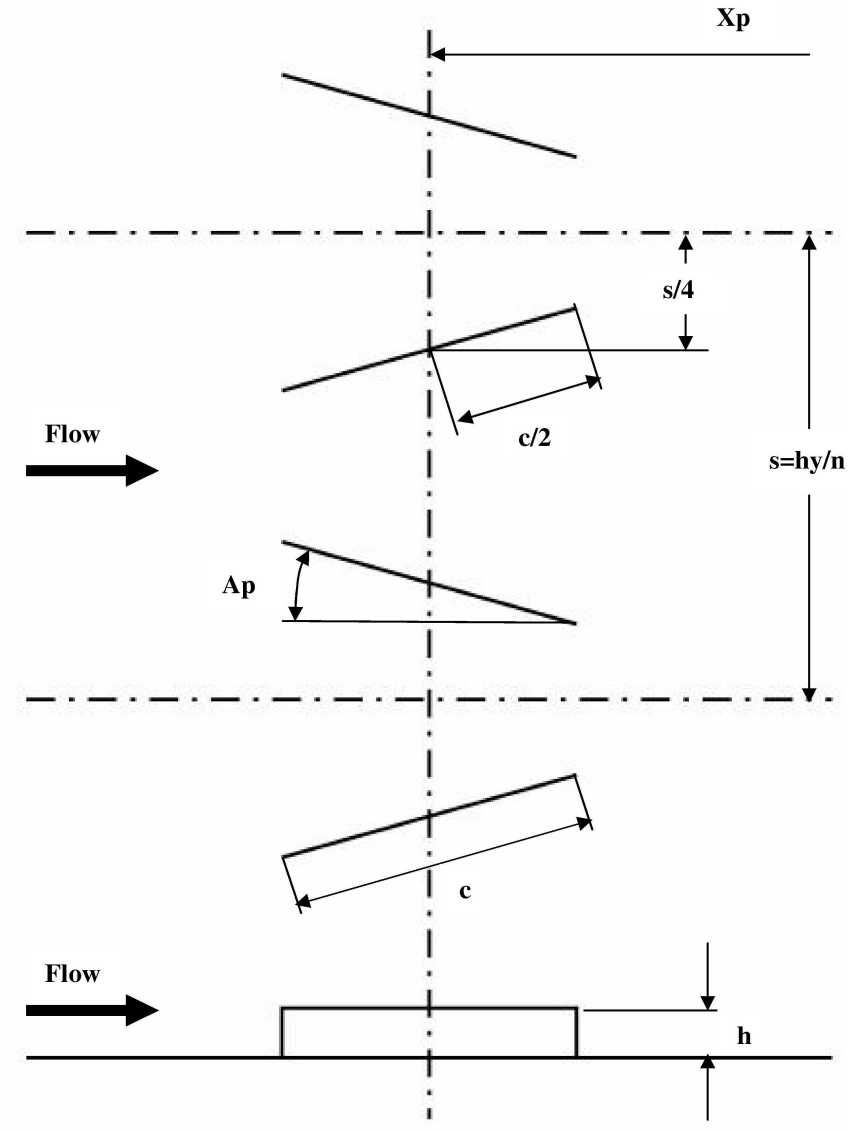

Figure (11): Geometry and nomenclature for standard micro-vane actuactors. 


\begin{tabular}{|c|c|}
\hline Factor & Range \\
\hline Number of micro-actuator pairs, $\mathrm{n}$ & 2.0 to 4.0 \\
\hline Micro-actuator angle of incidence, $(\mathrm{degs}), \mathrm{Ap}$ & 12.0 to 24.0 \\
\hline Micro-actuator height, $(\mathrm{mm}), \mathrm{h}$ & 3.0 to 5.0 \\
\hline Micro-actuator chord length $(\mathrm{mm}), \mathrm{c}$ & 12.0 to 36.0 \\
\hline Streamwise location of micro-actuators $(\mathrm{cm}), \mathrm{Xp}$ & 6.0 to 18.0 \\
\hline
\end{tabular}

Table (1): Factor variables which establish DOE design matrix.

\begin{tabular}{|c|c|}
\hline Variable & Value \\
\hline Tunnel Mach number, $\mathrm{M}_{\mathbf{0}}$ & $\mathbf{2 . 0}$ \\
\hline Shock generator angle $(\mathbf{d e g s}), \delta$ & 10.0 \\
\hline Tunnel total pressure $\left(\mathbf{l b s} / \mathbf{f t}^{2}\right), \mathbf{P}_{\mathbf{0}}$ & $\mathbf{2 1 1 2 . 0}$ \\
\hline Tunnel total temperature $\left({ }^{0} \mathbf{R}\right), \mathbf{T}_{\mathbf{0}}$ & $\mathbf{5 1 7 . 0}$ \\
\hline
\end{tabular}

Table (2): Variable held constant.

\begin{tabular}{|c|c|}
\hline Response & Nomenclature \\
\hline Total pressure change & $\mathbf{D P} / \mathbf{P}_{\mathbf{0}}$ \\
\hline Compressible displacement thickness (cm) & $\delta *$ \\
\hline Compressible momentum thickness (cm) & $\theta$ \\
\hline Transformed boundary layer form factor & $\mathbf{H}_{\mathrm{tr}}$ \\
\hline
\end{tabular}

Table (3): DOE response variables.
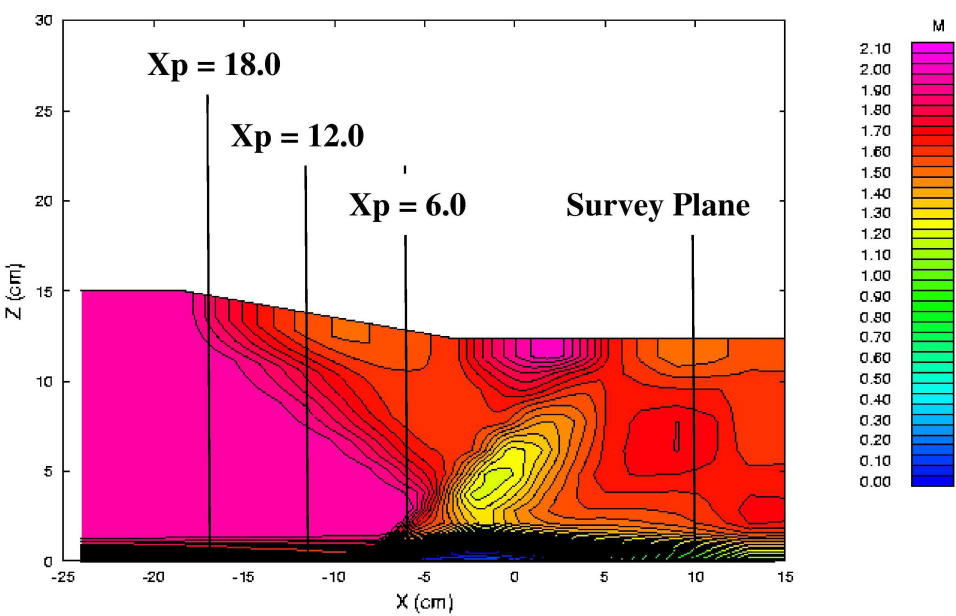

Figure (12): Location of micro-actuator arrays relative to the baseline shock wave boundary layer interaction, $M_{0}=2.0, \delta=10.0^{\circ}$.

\begin{tabular}{|c|c|c|c|c|c|}
\hline Config. & n & Ap (degs) & $\mathbf{h}(\mathrm{mm})$ & c (mm) & $\mathrm{Xp}(\mathrm{cm})$ \\
\hline nvg301 & 2.0 & 12.0 & 3.0 & 12.0 & 18.0 \\
\hline nvg302 & 4.0 & 12.0 & 3.0 & 12.0 & 6.0 \\
\hline nvg303 & 2.0 & 24.0 & 3.0 & 12.0 & 6.0 \\
\hline nvg304 & 4.0 & 24.0 & 3.0 & 12.0 & 18.0 \\
\hline nvg305 & 2.0 & 12.0 & 5.0 & 12.0 & 6.0 \\
\hline nvg306 & 4.0 & 12.0 & 5.0 & 12.0 & 18.0 \\
\hline nvg307 & 2.0 & 24.0 & 5.0 & 12.0 & 18.0 \\
\hline nvg308 & 4.0 & 24.0 & 5.0 & 12.0 & 6.0 \\
\hline nvg309 & 2.0 & 12.0 & 3.0 & 36.0 & 6.0 \\
\hline nvg310 & 4.0 & 12.0 & 3.0 & 36.0 & 18.0 \\
\hline nvg311 & 2.0 & 24.0 & 3.0 & 36.0 & 18.0 \\
\hline nvg312 & 4.0 & 24.0 & 3.0 & 36.0 & 6.0 \\
\hline nvg313 & 2.0 & 12.0 & 5.0 & 36.0 & 18.0 \\
\hline nvg314 & 4.0 & 12.0 & 5.0 & 36.0 & 6.0 \\
\hline nvg315 & 2.0 & 24.0 & 5.0 & 36.0 & 6.0 \\
\hline nvg316 & 4.0 & 24.0 & 5.0 & 36.0 & 18.0 \\
\hline nvg317 & 2.0 & 18.0 & 4.0 & 24.0 & 12.0 \\
\hline nvg318 & 3.0 & 18.0 & 4.0 & 24.0 & 12.0 \\
\hline nvg319 & 3.0 & 12.0 & 4.0 & 24.0 & 12.0 \\
\hline nvg320 & 3.0 & 24.0 & 4.0 & 24.0 & 12.0 \\
\hline nvg321 & 3.0 & 18.0 & 3.0 & 24.0 & 12.0 \\
\hline nvg322 & 3.0 & 18.0 & 5.0 & 24.0 & 12.0 \\
\hline nvg323 & 3.0 & 18.0 & 4.0 & 12.0 & 12.0 \\
\hline nvg324 & 3.0 & 18.0 & 4.0 & 36.0 & 12.0 \\
\hline nvg325 & 3.0 & 18.0 & 4.0 & 24.0 & 6.0 \\
\hline nvg326 & 3.0 & 18.0 & 4.0 & 24.0 & 18.0 \\
\hline nvg327 & 2.0 & 18.0 & 4.0 & 24.0 & 12.0 \\
\hline
\end{tabular}

Table (4): Central Composite Face-Centered (CCF) Design-of-Experiment (DOE) design matrix used in the micro-actuator array study.
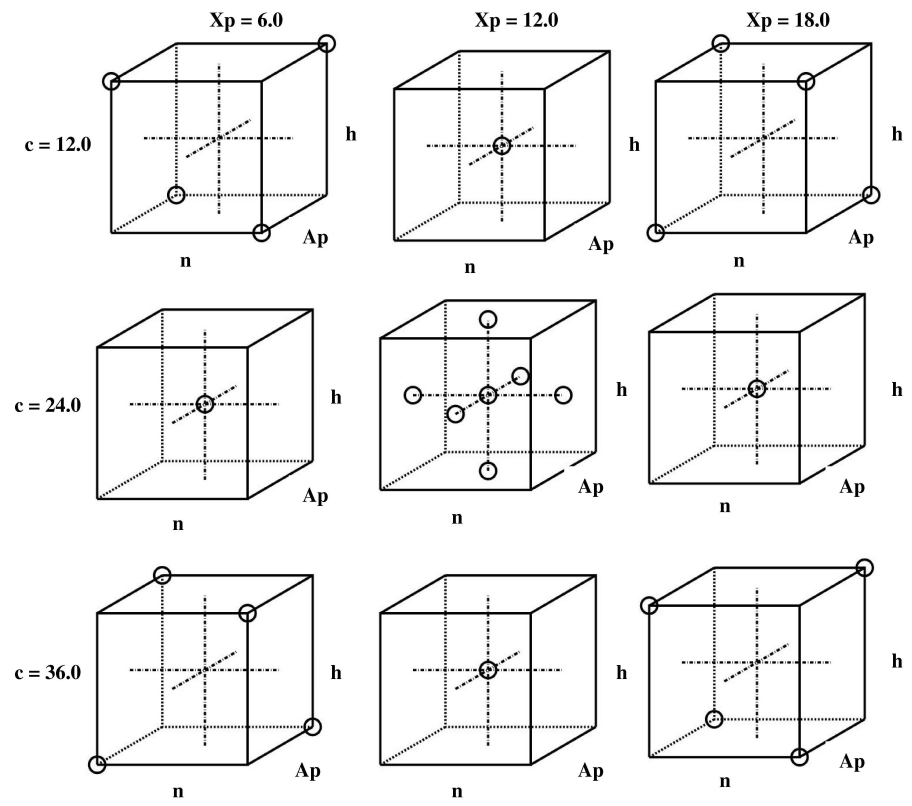

Figure (13): Graphical representation of the Central Composite Face-Centered (CCF) DOE design matrix used in the micro-actuator array study. 


\begin{tabular}{|c|c|c|c|c|c|c|c|}
\hline Config. & $\mathrm{w}_{1}$ & $\mathrm{w}_{2}$ & $\mathrm{n}$ & $\mathrm{Ap}$ & $\mathrm{h}(\mathrm{mm})$ & $\mathrm{c}(\mathrm{mm})$ & Xp \\
\hline nvg331 & $\mathbf{0 . 0}$ & 1.0 & 3.0 & 24.0 & 3.0 & 34.8 & 18.0 \\
\hline nvg431 & $\mathbf{0 . 0}$ & 1.0 & 4.0 & 24.0 & 5.0 & 36.0 & 18.0 \\
\hline nvg531 & $\mathbf{0 . 0}$ & 1.0 & 2.9 & 22.0 & 3.0 & 36.0 & 17.4 \\
\hline nvg332 & $\mathbf{0 . 5}$ & 0.5 & 3.1 & 22.2 & 3.1 & 28.8 & 18.0 \\
\hline nvg432 & $\mathbf{0 . 5}$ & $\mathbf{0 . 5}$ & 4.0 & 24.0 & 4.5 & 32.2 & 18.0 \\
\hline nvg532 & 0.5 & 0.5 & 2.0 & 24.0 & 3.0 & 12.0 & 18.0 \\
\hline nvg333 & 1.0 & 0.0 & 3.2 & 12.0 & 3.0 & 21.6 & 18.0 \\
\hline nvg433 & 1.0 & 0.0 & 4.0 & 12.0 & 3.9 & 24.0 & 18.0 \\
\hline nvg533 & 1.0 & 0.0 & 2.0 & 12.0 & 3.0 & 12.0 & 18.0 \\
\hline
\end{tabular}

Table (5): DOE validation test cases containing the nine (9) optimal micro-actuator array designs.

\begin{tabular}{|c|c|c|c|c|}
\hline Config. & $\mathbf{D P} / \mathbf{P}_{0}$ & $\delta^{*}(\mathrm{~cm})$ & $\theta(\mathrm{cm})$ & Htr \\
\hline nvg331 & 0.00437 & 0.45516 & 0.20700 & 1.33337 \\
\hline nvg431 & 0.00707 & 0.49252 & 0.21668 & 1.30702 \\
\hline nvg531 & -0.00693 & 0.54104 & 0.23401 & 1.31632 \\
\hline nvg332 & 0.00549 & 0.47082 & 0.20580 & 1.33656 \\
\hline nvg432 & 0.01336 & 0.56607 & 0.20268 & 1.34971 \\
\hline nvg532 & 0.01337 & 0.54028 & 0.21422 & 1.34971 \\
\hline nvg333 & 0.00730 & 0.51935 & 0.21512 & 1.38013 \\
\hline nvg433 & 0.01179 & 0.44481 & 0.18566 & 1.37850 \\
\hline nvg533 & 0.01537 & 0.56607 & 0.24266 & 1.39677 \\
\hline
\end{tabular}

Table (6): DOE prediction results for the nine (9) validation test cases defined by the DOE matrix in Table (5).

\begin{tabular}{|c|c|c|c|c|}
\hline Config. & DP/ P $_{0}$ & $\delta^{*}(\mathrm{~cm})$ & $\theta(\mathrm{cm})$ & Htr \\
\hline nvg331 & $\mathbf{- 0 . 0 0 0 1 1}$ & $\mathbf{0 . 5 2 0 7 4}$ & $\mathbf{0 . 2 3 7 5 7}$ & 1.34262 \\
\hline nvg431 & $\mathbf{0 . 0 0 5 1 9}$ & $\mathbf{0 . 4 9 2 8 2}$ & $\mathbf{0 . 2 2 9 4 4}$ & 1.32535 \\
\hline nvg531 & $\mathbf{0 . 0 0 4 0 4}$ & $\mathbf{0 . 5 0 3 6 9}$ & $\mathbf{0 . 2 3 1 7 3}$ & 1.31458 \\
\hline nvg332 & $\mathbf{0 . 0 0 4 2 8}$ & $\mathbf{0 . 4 9 8 7 7}$ & $\mathbf{0 . 2 2 5 8 5}$ & 1.35553 \\
\hline nvg432 & $\mathbf{0 . 0 0 7 1 1}$ & $\mathbf{0 . 4 8 1 7 9}$ & $\mathbf{0 . 2 1 8 8 0}$ & 1.33661 \\
\hline nvg532 & $\mathbf{0 . 0 0 6 0 4}$ & $\mathbf{0 . 4 8 5 2 4}$ & $\mathbf{0 . 2 1 3 4 1}$ & 1.37720 \\
\hline nvg333 & $\mathbf{0 . 0 0 6 3 3}$ & $\mathbf{0 . 5 0 7 3 7}$ & $\mathbf{0 . 2 2 8 3 0}$ & $\mathbf{1 . 3 7 0 4 5}$ \\
\hline nvg433 & $\mathbf{0 . 0 0 8 9 7}$ & $\mathbf{0 . 4 8 0 3 4}$ & $\mathbf{0 . 2 0 6 6 8}$ & $\mathbf{1 . 4 0 9 7 5}$ \\
\hline nvg533 & $\mathbf{0 . 0 1 1 4 5}$ & $\mathbf{0 . 4 6 8 5 4}$ & $\mathbf{0 . 1 9 3 2 5}$ & 1.40469 \\
\hline
\end{tabular}

Table (7): CFD analysis results for the nine (9) validation test cases defined by the DOE matrix in Table (5).

\begin{tabular}{|c|c|c|c|c|c|}
\hline Response & MEAN & STDEV & $\mathbf{t}^{*}$ & $\mathbf{t}(\mathbf{0 . 9 7 5 , 8})$ & Comment \\
\hline$\Delta\left(\mathrm{DP} / \mathbf{P}_{\mathbf{0}}\right)$ & $\mathbf{0 . 0 0 3 3}$ & $\mathbf{0 . 0 0 5 3}$ & $\mathbf{0 . 6 2 0 1}$ & $\mathbf{2 . 3 0 6}$ & Not Diff. \\
\hline$\Delta \delta^{*}$ & $\mathbf{0 . 0 1 7 4 2}$ & $\mathbf{0 . 0 4 5 4}$ & $\mathbf{0 . 3 8 3 4}$ & $\mathbf{2 . 3 0 6}$ & Not Diff. \\
\hline$\Delta \theta$ & $\mathbf{- 0 . 0 0 6 8}$ & $\mathbf{0 . 0 2 3 5}$ & $\mathbf{0 . 2 8 9 9}$ & $\mathbf{2 . 3 0 6}$ & Not Diff. \\
\hline$\Delta \mathbf{H}_{\text {tr }}$ & $\mathbf{- 0 . 0 1 0 3}$ & $\mathbf{0 . 0 1 5 7}$ & $\mathbf{0 . 6 5 3 1}$ & $\mathbf{2 . 3 0 6}$ & Not Diff. \\
\hline
\end{tabular}

Table (8): Paired t-test statistical evaluation between the nine (9) optimal DOE prediction cases, Table (6), and the nine (9) optimal CFD analysis cases, Table (7).

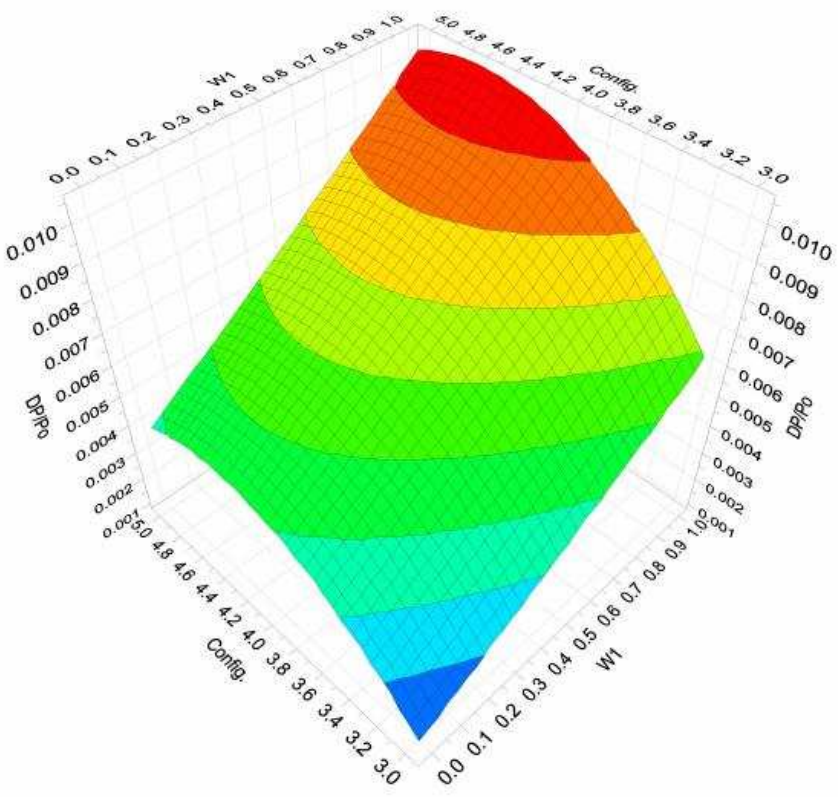

Figure (13): DP/ $\mathbf{P}_{0}$ response surface containing the optimal micro-actuactor array designs defined by the DOE in Table (5).

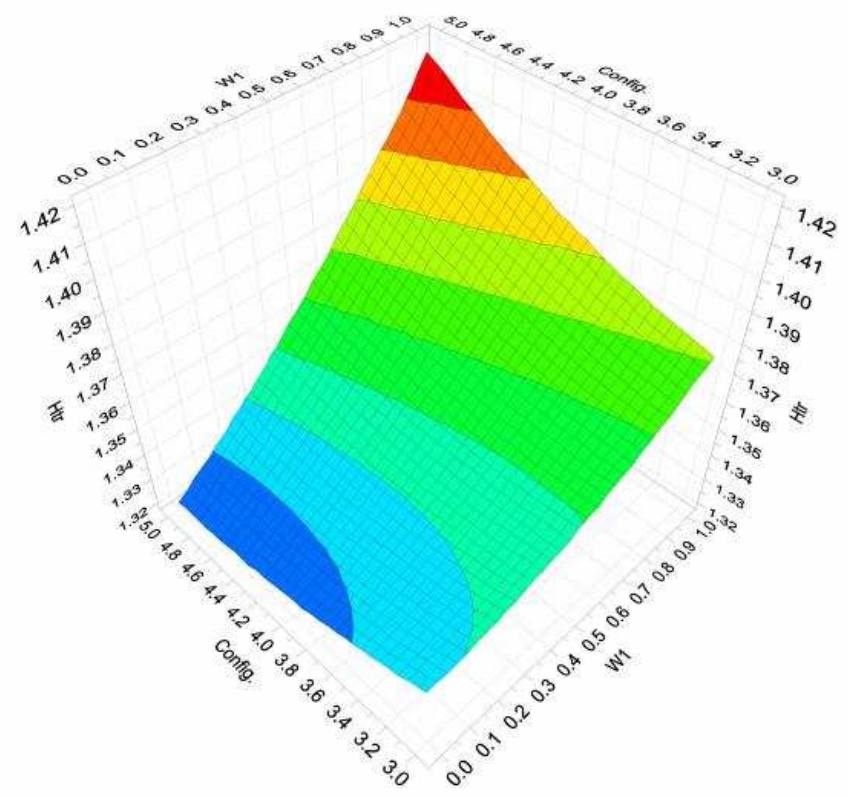

Figure (13): $H_{t r}$ response surface containing the optimal micro-actuactor array designs defined by the DOE in Table (5). 


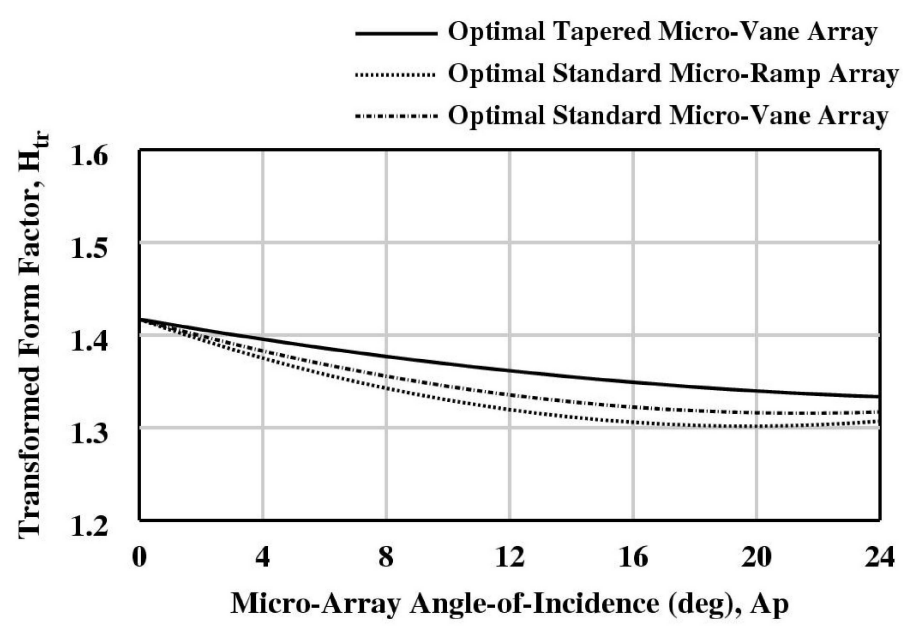

(a) Optimal micro-actuator array performance, $w_{1}=0.0$, $\mathbf{w} 2=1.0$.

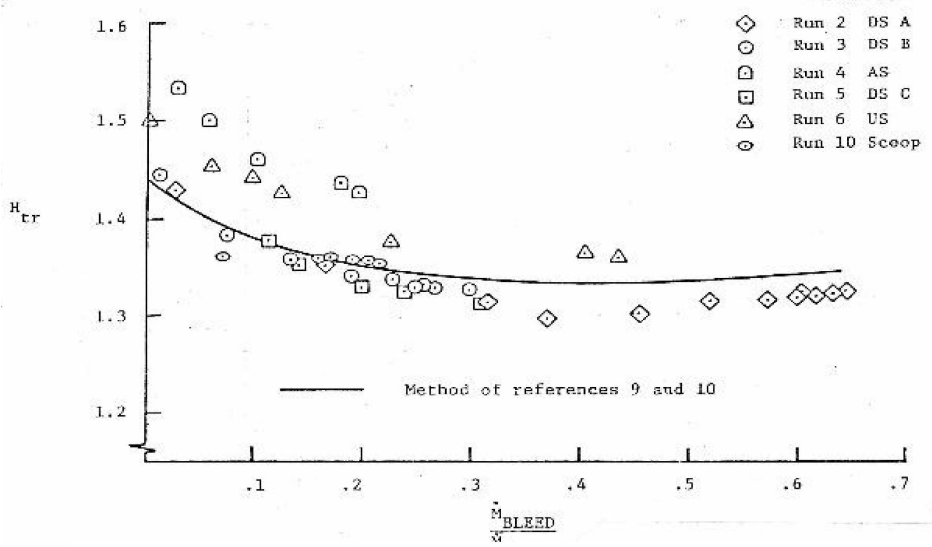

(b) Optimal boundary layer bleed performance, $W_{\text {bleed }} / W_{0}=1.87 \%$.

Figure (14): Comparison between optimal micro-actuator array $\mathrm{H}_{\mathrm{tr}}$ performance and optimal boundary layer bleed $\mathbf{H}_{\text {tr }}$ performance, (Ref. 2).

\begin{tabular}{|c|c|c|c|c|c|c|c|}
\hline Config. & $\mathbf{w}_{1}$ & $\mathbf{w}_{2}$ & $\mathrm{~s} / \mathbf{h}$ & Ap & $\mathbf{h} / \delta_{\text {shk }}$ & $\mathrm{c} / \mathbf{h}$ & $X p / \delta_{\text {shk }}$ \\
\hline nvg331 & 0.0 & 1.0 & 16.7 & 24.0 & 0.24 & 11.6 & 14.2 \\
\hline nvg431 & 0.0 & 1.0 & 7.5 & 24.0 & 0.40 & 7.2 & 14.2 \\
\hline nvg531 & 0.0 & 1.0 & 17.2 & 22.0 & 0.24 & 12.0 & 13.7 \\
\hline nvg332 & 0.5 & 0.5 & 15.6 & 22.2 & 0.24 & 9.3 & 14.2 \\
\hline nvg432 & 0.5 & 0.5 & 8.3 & 24.0 & 0.36 & 7.2 & 14.2 \\
\hline nvg532 & 0.5 & 0.5 & 25.4 & 24.0 & 0.24 & 4.0 & 14.2 \\
\hline nvg333 & 1.0 & 0.0 & 15.6 & 12.0 & 0.24 & 7.2 & 14.2 \\
\hline nvg433 & 1.0 & 0.0 & 9.6 & 12.0 & 0.31 & 6.2 & 14.2 \\
\hline nvg533 & 1.0 & 0.0 & 25.0 & 12.0 & 0.24 & 4.0 & 14.2 \\
\hline
\end{tabular}

Table (9): General micro-actuator array design guidelines.

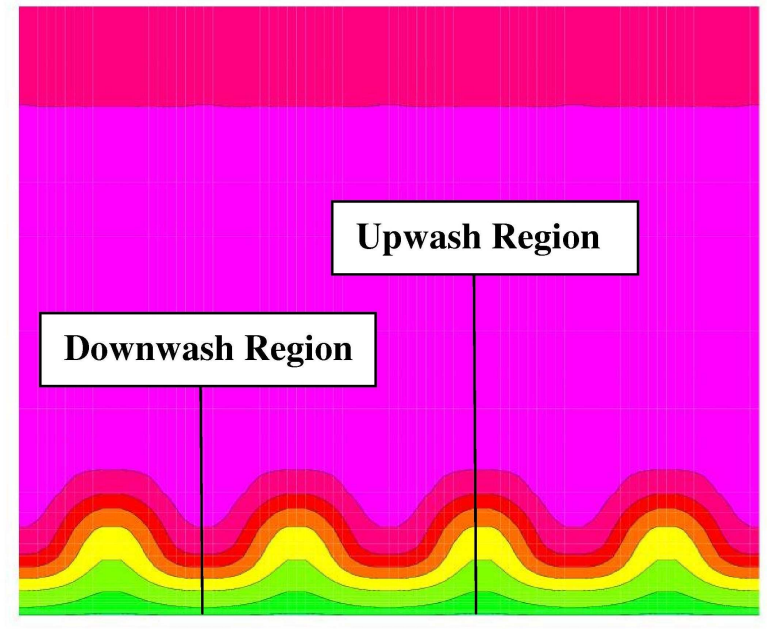

Figure(15): Spanwise total pressure contours for the optimal micro-ramp array, Config. nvg431.
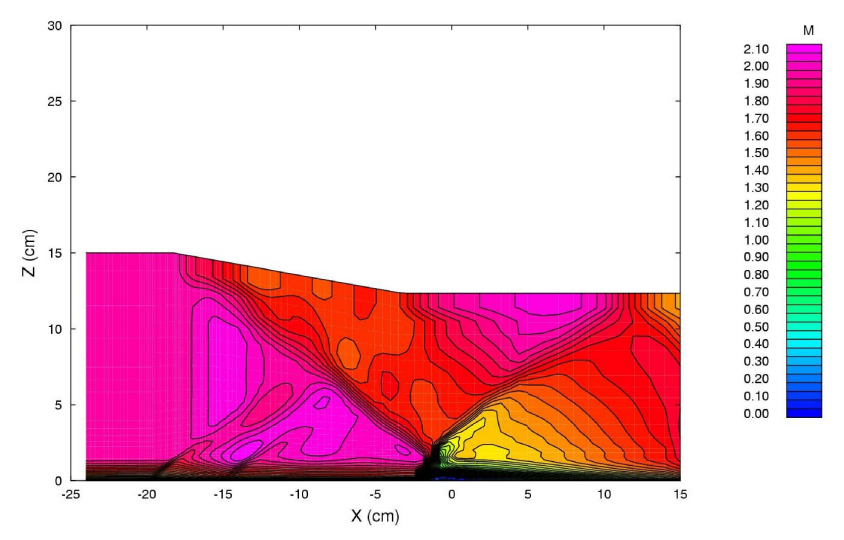

(a) Streamwise plane in downwash region.
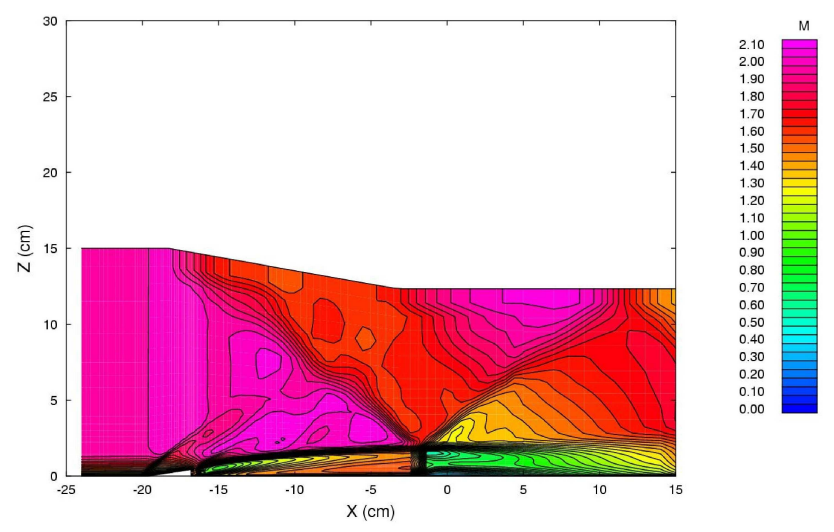

(b) Streamwise plane in upwash region.

Figure(16): Streamwise Mach number contours for the optimal micro-ramp array, Config. nvg431. 
Public reporting burden for this collection of information is estimated to average 1 hour per response, including the time for reviewing instructions, searching existing data sources, gathering and maintaining the data needed, and completing and reviewing the collection of information. Send comments regarding this burden estimate or any other aspect of this collection of information, including suggestions for reducing this burden, to Washington Headquarters Services, Directorate for Information Operations and Reports, 1215 Jefferson Davis Highway, Suite 1204, Arlington, VA 22202-4302, and to the Office of Management and Budget, Paperwork Reduction Project (0704-0188), Washington, DC 20503.

\begin{tabular}{|l|l|l|}
\hline 1. AGENCY USE ONLY (Leave blank) & $\begin{array}{c}\text { 2. REPORT DATE } \\
\text { December } 2006\end{array}$ & $\begin{array}{r}\text { 3. REPORT TYPE AND DATES COVERED } \\
\text { Technical Memorandum }\end{array}$
\end{tabular}

\section{TITLE AND SUBTITLE}

5. FUNDING NUMBERS

Optimal Control of Shock Wave Turbulent Boundary Layer Interactions Using

Micro-Array Actuation

\section{AUTHOR(S)}

Bernhard H. Anderson, Jon Tinapple, and Lewis Surber

WBS 984754.02.07.03.03.01

\section{PERFORMING ORGANIZATION NAME(S) AND ADDRESS(ES)}

National Aeronautics and Space Administration

John H. Glenn Research Center at Lewis Field

Cleveland, Ohio 44135-3191

8. PERFORMING ORGANIZATION

REPORT NUMBER

$$
\text { E-15654 }
$$

\section{SPONSORING/MONITORING AGENCY NAME(S) AND ADDRESS(ES)}

National Aeronautics and Space Administration

Washington, DC 20546-0001

10. SPONSORING/MONITORING AGENCY REPORT NUMBER

NASA TM-2006-214373

AIAA-2006-3197

\section{SUPPLEMENTARY NOTES}

Prepared for the Third Flow Control Conference sponsored by the American Institute of Aeronautics and Astronautics,

San Francisco, California, June 5-8, 2006. Bernhard H. Anderson, Glenn Research Center; Jon Tinapple, Air Force

Research Laboratory, Wright-Patterson Air Force Base, Dayton, Ohio 45433; Lewis Surber, Universal Technology Corporation, 1270 North Fairfield Road, Dayton, Ohio 45432. Responsible person, Bernhard H. Anderson, organization code RTE, 216-433-5822.

12a. DISTRIBUTION/AVAILABILITY STATEMENT

12b. DISTRIBUTION CODE

Unclassified - Unlimited

Subject Categories: 02 and 07

Available electronically at http://gltrs.grc.nasa.gov

This publication is available from the NASA Center for AeroSpace Information, 301-621-0390.

13. ABSTRACT (Maximum 200 words)

The intent of this study on micro-array flow control is to demonstrate the viability and economy of Response Surface Methodology (RSM) to determine optimal designs of micro-array actuation for controlling the shock wave turbulent boundary layer interactions within supersonic inlets and compare these concepts to conventional bleed performance. The term micro-array refers to micro-actuator arrays which have heights of 25 to 40 percent of the undisturbed supersonic boundary layer thickness. This study covers optimal control of shock wave turbulent boundary layer interactions using standard micro-vane, tapered micro-vane, and standard micro-ramp arrays at a free stream Mach number of 2.0. The effectiveness of the three micro-array devices was tested using a shock pressure rise induced by the $10^{\circ}$ shock generator, which was sufficiently strong as to separate the turbulent supersonic boundary layer. The overall design purpose of the micro-arrays was to alter the properties of the supersonic boundary layer by introducing a cascade of counter-rotating micro-vortices in the near wall region. In this manner, the impact of the shock wave boundary layer (SWBL) interaction on the main flow field was minimized without boundary bleed.

\section{SUBJECT TERMS}

Aerodynamics; Propulsion and power

15. NUMBER OF PAGES

20

16. PRICE CODE

\begin{tabular}{|c|c|c|}
\hline $\begin{array}{c}\text { 17. SECURITY CLASSIFICATION } \\
\text { OF REPORT } \\
\text { Unclassified }\end{array}$ & $\begin{array}{c}\text { 18. SECURITY CLASSIFICATION } \\
\text { OF THIS PAGE } \\
\text { Unclassified }\end{array}$ & $\begin{array}{c}\text { 19. SECURITY CLASSIFICATION } \\
\text { OF ABSTRACT } \\
\text { Unclassified }\end{array}$ \\
\hline
\end{tabular}

NSN 7540-01-280-5500

Standard Form 298 (Rev. 2-89) 

